\title{
UWB Circular Fan-Shaped Monopole Patch Antenna
}

\author{
P. More, A. Patil, G. Patil, K. Thakur and D. Marathe \\ JES, A.C. Patil College of Engineering, Kharghar, Navi-Mumbai, Maharashtra, India \\ Email: deepak.acp@gmail.com
}

Received: 26 January 2021; Accepted: 01 March 2021; Published: 08 April 2021

\begin{abstract}
In this paper, a fan-shaped ultra- wideband (UWB) microstrip patch antenna is re- ported. The antenna is designed, simulated, fab- ricated, and tested. The antenna operates over a $3.1 \mathrm{GHz}-6 \mathrm{GHz}$ for Wireless Capsule Endoscopy (WCE) applications with VSWR less than 2 and return loss is lower than $-10 \mathrm{~dB}$. The antenna is a monopole circular structure with radius of $10.2 \mathrm{~mm}$ and ground plane dimension $24 \times 16 \mathrm{~mm}$ (" $\mathrm{Lg}$ x Wg") is designed on substrate FR4. The impedance matching and radiation characteristics of the designed structure are investigated. The pro- posed antenna with small size and different ground structure is considered to reduce the surface wave and to achieves high impedance bandwidth and good gain performance for ultra-wide band (UWB) range with specific absorption rate (SAR) $1.126 \mathrm{~W} / \mathrm{kg}$ for $10 \mathrm{~g}$ of tissue.
\end{abstract}

Index Terms: Wireless Capsule Endoscopy (WCE), Ultra-Wide Band (UWB), Circular, Monopole, Omni-directional, Specific Absorption Rate (SAR).

\section{Introduction}

Implantable medical devices are used to per- form a wide variety of diagnostic and therapeu- tic function. With the help of biotelemetry and integrated implantable antenna full duplex com- munication is made possible between implantable antennas with on body receiver antennas for in- body communication system. Also, wireless communication makes inroads into every aspect of human life. Designing an antenna for implanted application is difficult because of different elec- trical properties of human tissue. Also, size of antenna at low frequency is a very crucial fac- tor. Implantable medical devices can communicate wirelessly with an external device. Biomedical telemetry can be both real time and stored physical signals can also be communicated to the receiver. As per the commendation of FCC, Medical Im- plant communication Services (MICS) band of 402-406 MHz is recommended for implantable antennas. MICS band has replaced previous low frequency inductive link, which suffers from slow data rate, short range communication. The maxi- mum transmit power requirement at this band is very low, about 25 microwatts. This reduces the risk of interference with other users of the same band. The maximum used bandwidth at a time is $300 \mathrm{KHz}$, which makes it a low bit rate system compared with Wi-Fi or Bluetooth. Implanted devices are inserted into human body and im- plantable antenna ensures wireless bio-telemetry. Therefore, the antenna design is very crucial part in implantable device. Microstrip patch antennais preferred as it is a narrowband, wide-beam antenna [1, 2].

\section{Literature Review}

Endoscopy is a nonsurgical procedure used to examine a patient's digestive tract such as stom- ach, colon and rectum. This conventional invasive wired endoscopy technique causes intense pain for patients, infection because of leaving the small Intestine as a dead zone. It cannot examine the whole Given Imaging (GI) tract. The limitations in invasive method so the most popular Wireless Capsule Endoscopy (WCEs), are developed and manufactured by Olympus (Olympus, 2010), In- troMedic (IntroMedic, 2010) and Given Imaging (Given Imaging, 2010) [3]. The disease character-istics of a human body part like stomach, large bowel or colon, and part of the small bowel after being swallowed are observed using an ingestible capsule WCE. It can take and send pictures in real-time of the digestive tract. For real-time data transfer from and to the capsule, antennas with wide-bandwidth capabilities are required [4]. The communication of WCE requires a transmitter with a wide bandwidth and compact size for signal transmission through the human body. [5].

The antenna plays a vital role when it is at- tempted to communicate with an ingestible device [6]. The painless wireless ingestible capsule sys- tem occurred as a perfect choice to the traditional method. But lot of factors (such as radius of capsule, the shell thickness, and internal battery) affect the performances of transmitting antenna in WCE 
system which includes impedance band- width, gain, size, sensitivity to the surrounding environment, detuning effects, polarization shift and radiation safety. The antenna should have pri- mary requirement as miniaturization for wireless ingestible devices [7]. The major challenges need to overcome in designing a transmitting antenna for WCE system were antenna size miniaturiza- tion, maintaining wide bandwidth, achieving near- omnidirectional radiation pattern, maintaining al- lowable SAR etc.

Many researchers have been worked for the de- signing of high performance and compact antenna for WCE in different frequency bands. They come up with different geometrical shaped antennas type in [8, 9] and the conformal meandered type antennas reported in $[10,11,12]$ are developed in different frequency bands. These antennas have a narrow band and low data rate. There is re- quirement of UWB frequency band with compact planar slotted patched antenna to operate inside a human body. To increase the bandwidth of the antenna, multiple slots with different geometrical shapes are etched on the patch. The bandwidth obtained by this method is $1.84 \mathrm{GHz}$ inside a simplified human body model. Compare to other papers of WCE antennas, it has miniature size and exhibits higher bandwidth [4] whereas U-shaped antenna [13] gives wider Bandwidth $2.268 \mathrm{GHz}$.

In section II, a fan-shaped patch antenna struc- ture design, simulation and its implementation are discussed. The results and discussions are mentioned in section III. Section IV describes the conclusion.

\section{Objective}

The main challenges of WCE antenna are size miniaturization, choosing non-toxic substrate, achieving omnidirectional radiation pattern, main-taining the allowable SAR and wide Bandwidth.

In order to achieve wide bandwidth frequency and SAR need to be increases. But to maintain the allowable SAR, SAR need to be reduce.

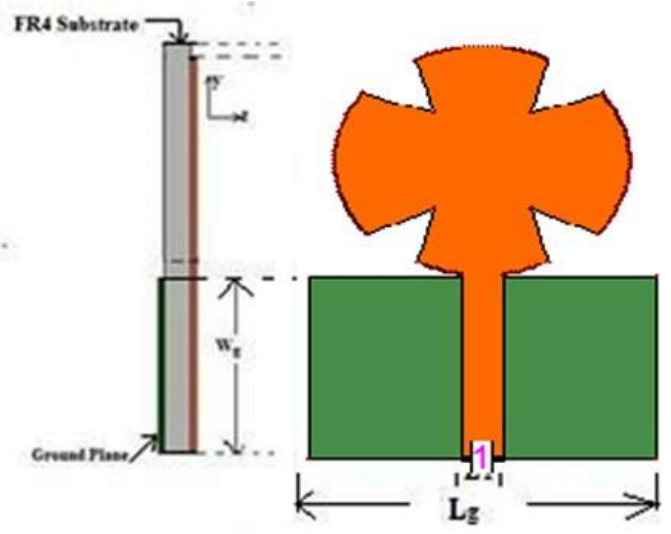

Fig. 1. Geometry of circular monopole Antenna.

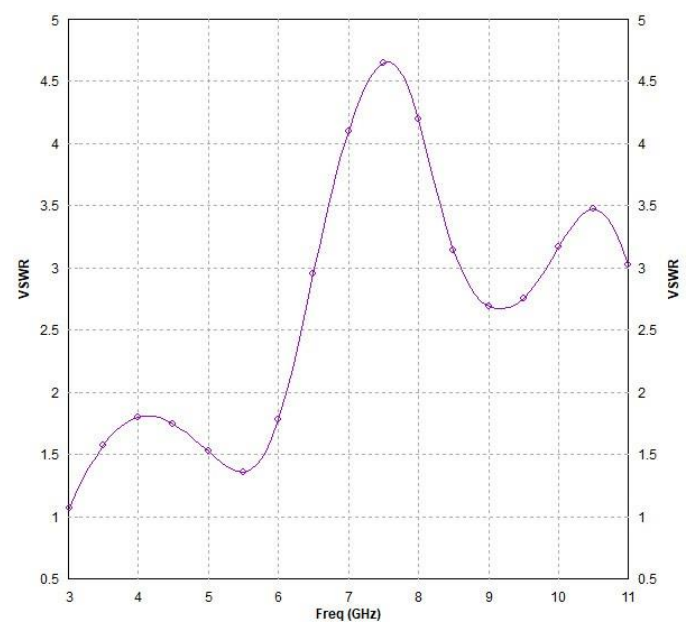

Fig. 2. Frequency versus VSWR for proposed UWB band antenna. 
is determined using Eq. 1, considering the lowerresonant frequency (LF) as $3.1 \mathrm{GHz}$ [14].

$$
L F=\frac{7.2}{(2.25 * R)+g}
$$

to decreases and which increases the size of antenna. Another way to reduce SAR is transm- itting power need to be reduce which may result into the low data rate. Therefore, one has to achieve tradeoff between SAR, data rate and miniaturization.

\section{Methodology}

A proposed UWB patch antenna is designed with 4.4 relative permittivity, 0.025 as a loss tangent, and radius "R" on $1.5 \mathrm{~mm}$ FR4 is shown in Fig. 1. The substrate has a conducting ground plane with a length "Lg" and width "Wg". In order to achieve $50 \Omega$ impedance match the width of a micro-strip feed line is calculated and optimized. The radius of the patch, where, $L F$ is the resonant lower frequency in $\mathrm{GHz}, R$ is a circular patch radius in centimeters $(\mathrm{cm})$, and $g$ is the gap between patch and ground plane in centimeters $(\mathrm{cm})$.

\section{Design Consideration of Fan-Shaped Antenna and its Radiation Pattern}

The main requirement of WCE antenna is hav- ing wide bandwidth because it directly determines the communication data rate. WCE systems able to complete transmission of high-resolution images from and to capsule in real time then high data rate and hence wide bandwidth is essential. Also miniaturization of the antenna is a key issue to save the precious space of capsules and also it become easier to swallow by patient. In addition, antenna should have omnidirectional radiation pat- tern for reliable transmission of data regardless of the orientation and location of the capsule. In order to prevent hazardous heating of the biological tissues, antenna must have satisfy the SAR safety limits. According to IEEE C95.1-1999 standard restricts the SAR value averaged over any $1 \mathrm{~g}$ of tissue in the shape of a cube (1 g-AVG SAR) to less than 1.6 W/kg and IEEE C95.1-2005 standard restricts the SAR averaged over any $10 \mathrm{~g}$ of tissue in the shape of a cube (10-g AVG SAR) to less than $2 \mathrm{~W} / \mathrm{kg}$.

\section{A. Patch Radius $(R)$ and Its Effect}

The frequency variation and effect patch radius "R" onto fan-shaped circular patch antenna is analyzed. This effect w.r.t. the return loss for frequency variations is shown in Fig. 2. The value of VSWR is less than 2 up to $6 \mathrm{GHz}$ frequency and resonance get shifted to lower frequencies with the increase in radius. The fan-shaped antenna has omnidirectional characteristics at $3.1 \mathrm{GHz}$ and its radiation pattern for different radius are shown in Fig. 3. As frequency increases the antenna losses its omnidirectional pattern. The change in radius

(R) from $10.2 \mathrm{~mm}$ to $12 \mathrm{~mm}$ causes to increasein the cross-polar component.

\section{B. Ground Plane Dimensions and Its Effect}

The ground plane dimensions are contribut- ing on radiation pattern of an antenna and an impedance bandwidth. The investigation of " $\mathrm{Lg}$ " and " $\mathrm{Wg}$ " with optimized patch radius of $10.2 \mathrm{~mm}$ is carried out. The simulated Sparameter for proposed antenna with different " $\mathrm{Lg}$ " i .e. $16 \mathrm{~mm}, 20 \mathrm{~mm}$, and $24 \mathrm{~mm}$ is shown in Fig. 4. The ground plane width " Wg" i.e. $14 \mathrm{~mm}, 16 \mathrm{~mm}$, and $18 \mathrm{~mm} \mathrm{~S}$-parameter is shown in Fig. 5. The changes in a resonant frequency due the widthis not significant compared to the ground plane length.

\section{Dielectric Constant and Its Effect}

An increase in cross-polar component for radius $\mathrm{R}=12 \mathrm{~mm}$ as compared to $\mathrm{R}=10.2 \mathrm{~mm}$ due to higher-order modes of excitation. The current $\mathrm{Jx}$ at the upper edge of a ground plane near the radiating patch changes the radiation pattern. The radiating patch dielectric interface, air, and the discontinuity at the substrate result in generation of surface waves. The radiation characteristics of an antenna in terms of resonant frequencies in radiation patterns can be improved by reducing dielectric constant and dielectric thickness. Hence, the radiation characteristics is investigated. The fanshaped antenna has a radius $10.2 \mathrm{~mm}$ and it is designed on ground plane as "Lg" $\mathrm{x}$ "Wg" $24 \mathrm{~mm} \times 16 \mathrm{~mm}$ with $1.6 \mathrm{~mm}$ FR4. The performance measurement of RT Duroid antenna designed on $0.787 \mathrm{~mm}$ with 0.0009 loss tangent and 2.2 relative permittivity. The investigation of antenna with patch radius is $10.2 \mathrm{~mm}$ and a ground plane as " $\mathrm{Lg} " \mathrm{x}$ " $\mathrm{W} "=$ $20 \mathrm{~mm} \times 13 \mathrm{~mm}$ is carried out.

\section{Results and Discussions}

There is a significant reduction in the cross- polar component by controlling the thickness of dielectric, the loss tangent and dielectric constant. Fig. 6, shows the frequency versus plot for RT Duroid and FR4. The change in a 
gain is seen all over UWB and which is notable at higher frequencies. An increase in the efficiency of an- tenna shown in Fig. 7, due to the reduction in a dielectric constant for FR4 and RT Duroid. The antenna radiation pattern for RT Duroid and FR4 at $3.1 \mathrm{GHz}$ frequency is shown in Fig. 8. The prototype is shown in Fig. 9. The monopole fanshaped antenna is proposed for WCE. It provides a return loss above $10 \mathrm{~dB}$ over an extremely wide frequency range. It was confirmed by simulation that quite good antenna for human body to operate inside using WCE capsule at UWB frequency band. Lower UWB monopole planar antenna with fan-shaped structure is designed using a substrate of thickness FR4 $(\mathrm{h})=1.5$ and permittivity FR4

(e) $=4.4$ with omnidirectional radiation character-istics.

\section{Conclusion}

Table I shows the comparison of different tech- niques used to improve the performance param- eters of a proposed antenna. It can be observed that in order to achieve wide bandwidth, there is a need of increasing frequency, if frequency increases SAR value also increases. To reduce SAR frequency, need to be reducing but it results into the large size. Another way to reduce SAR is transmitting power need to be reduce which may result into the low data rate. Therefore, one has to achieve trade-off between SAR, data rate and miniaturization. The gain of antenna improves by increasing efficiency with decrease in permittivity. Due to the structure simplicity, the VSWR, and

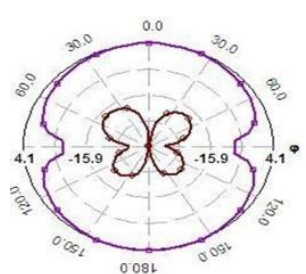

[a]

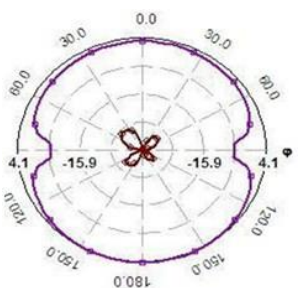

[b]

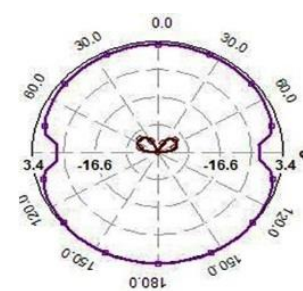

[c]

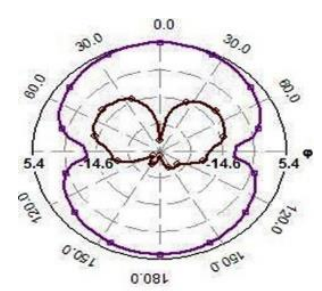

[d]

Fig. 3. Radiation pattern of antenna for different frequencies (a) $3.1 \mathrm{GHz}$ (b) $4.1 \mathrm{GHz}$ (c) $5.1 \mathrm{GHz}$ (d) $5.8 \mathrm{GHz}$

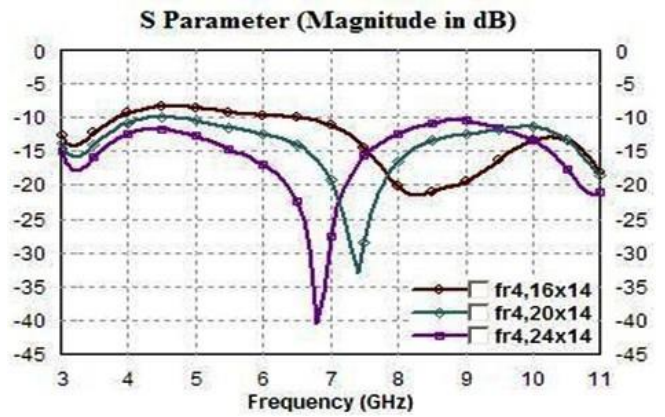

Fig. 4., Simulated S-parameter for proposed antenna with different " $\mathrm{Lg}$ ".

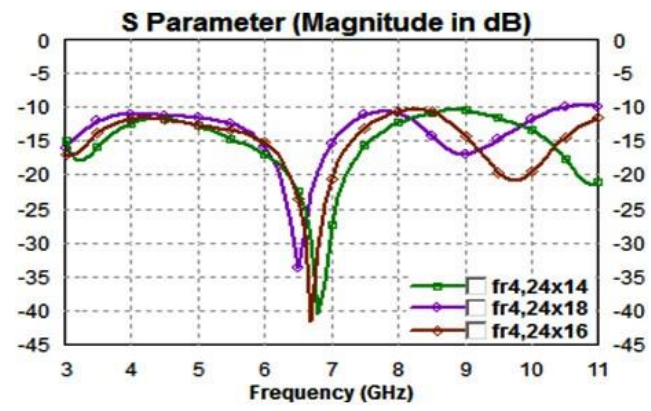

Fig. 5., Simulated S-parameter for proposed antenna with different "Wg". 


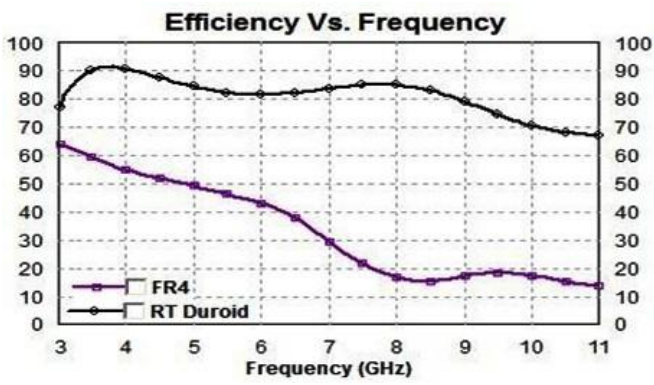

Fig. 6., Frequency versus Efficiency of FR4 and RT Duroid.

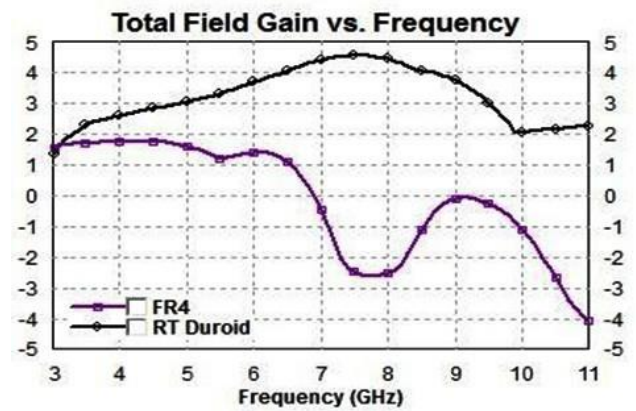

Fig. 7. Frequency versus Gain variation of FR4 and RT Duroid.

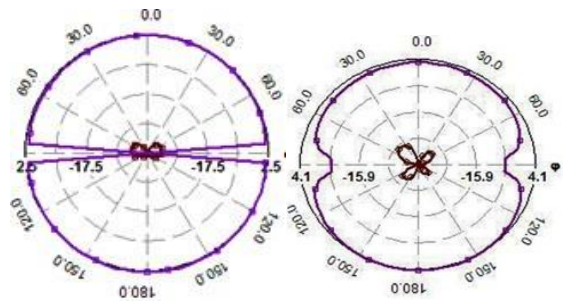

[a]

[b]

Fig. 8. Antenna radiation pattern with $3.1 \mathrm{GHz}$ for (a) RT Duroid (b) FR4 substrate.

Table 1., Comparison of different techniques for improving the performance of WCE antenna.

\begin{tabular}{|l|l|l|l|l|l|}
\hline References & Radiating structure & Patch size $(\mathrm{L} \times \mathrm{w} \times \mathrm{h}) \mathrm{mm}$ & R. L. (dB) & SAR limit (W/kg) & BW \\
\hline This work & $\begin{array}{l}\text { Circular fan-shaped } \\
\text { monopole patch antenna }\end{array}$ & $24 \times 16 \times 15$ & $\leq-10$ & $\begin{array}{l}11.483(1 \mathrm{~g} \text { of tissue }) \\
1.126(10 \mathrm{~g} \text { of tis- } \\
\text { sue })\end{array}$ & $3.1 \mathrm{GHz}$ \\
\hline$[13](2016)$ & $\begin{array}{l}\text { Meandered U-shaped } \\
\text { patch antenna }\end{array}$ & $28 \times 24 \times 0.787$ & -18 & $2.6(1 \mathrm{~g}$ of tissue $)$ & $2.268 \mathrm{GHz}$ \\
\hline$[5](2018)$ & $\begin{array}{l}\text { Outer wall conformal } \\
\text { patch antenna }\end{array}$ & $15 \times 15 \times 0.79$ & $\leq-10$ & $913(1 \mathrm{~g}$ of tissue $)$ & $541 \mathrm{MHz}$ \\
\hline$[4](2016)$ & Slotted patch antenna & $10 \times 10 \times 0.6$ & -20.4 & $45.24(10 \mathrm{~g}$ of tissue $)$ & $1.84 \mathrm{GHz}$ \\
\hline$[15](2019)$ & AMC based monopole & $4.6 \times 7.6 \times 0.15$ & -41 & $0.825(1 \mathrm{~g}$ of tissue $)$ & $5.8 \mathrm{GHz}$ \\
\hline
\end{tabular}

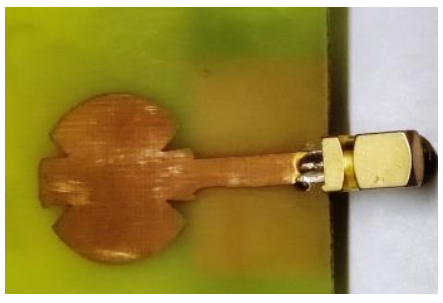

Fig. 9. Photo of the fabricated proposed circular monopole fan-shaped antenna. 


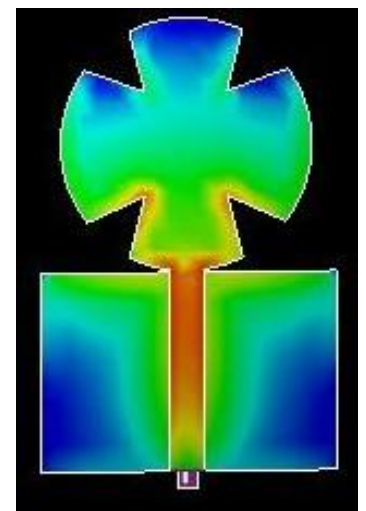

Fig. 10. Current distribution at $3.1 \mathrm{GHz}$.

\section{References}

[1] S. Manna, "Rectangular Microstrip Patch Antenna for Medical Application," Int. J. of Advance Research in Electrical, Electronics and Instrumentation Engineering,vol. 5, pp. 698-701, Feb. 2016.

[2] R Tiwari et al., "Design and Performance Analysis of a Triple Band Micro-Strip Patch Antenna with CPW- Fed," Int. J. of Wireless and Microwave Technologies (IJWMT), Vol.9, No.1, pp. 36-42, 2019.

[3] Z. Wang, E. G. Lim, T. Tillo, and F. Yu, "Review of the Wireless Capsule Transmitting and Receiving An- tennas," J. Wireless Communications and Networks-Recent Advances, 2012.

[4] F. Arifin and P. K. Saha, "Bandwidth Enhancement of a Compact Planar Antenna for Wireless Capsule En- doscopy," in Proc. 9th IEEE International Conferenceon Electrical and Computer Engineering (ICECE), Dec. 2016, pp. 411-414.

[5] J. Wang et al., "An Implantable and Conformal Antenna for Wireless Capsule Endoscopy." IEEE Antennas and Wireless Propagation Lett, May 2018.

[6] Z. Bao, Y. Guo and R. Mittra, "An Ultrawideband Con- formal Capsule Antenna With Stable Impedance Match- ing," in IEEE Trans. on Antennas and Propag., vol. 65, no. 10, pp. 5086-5094, Oct. 2017.

[7] T. M. Neebha, and M. Nesasudha, "Analysis of an Ultra Miniature Capsule Antenna for Gastrointestinal Endoscopy." in Int. Journal on Engineering Science and Technology, vol. 21, no. 5, Oct. 2018, pp. 938-944.

[8] C. Liu, Y.-X.Guo, and S. Xiao, "Circularly polarized he- lical antenna for ism-band ingestible capsule endoscope systems," IEEE Tran. Ant. and Pro., vol. 62, no. 12, pp. 6027-6039, 2014.

[9] S. Lee et al., "A wideband spiral antenna for ingestible capsule endoscope systems: experimental results in a hu- man phantom and a pig," IEEE Tran. on Biomedical Engineering, vol. 58, no. 6, pp. 1734-1741, 2011.

[10] X. Cheng et al., "An omnidirectional wrapable compact patch antenna for wireless endoscope applications," IEEE Ant. and Wireless Pro. Letters., vol. 11, pp. 1667 -1670, 2012.

[11] E. Lim et al., "The uhf band in-body antennas for wireless capsule endoscopy," Engineering Letters, vol. 21, no. 2, pp. 72-80, 2013.

[12] R. Alrawashdeh, Y. Huang, P. Cao, and E. Lim, "A new small conformal antenna for capsule endoscopy," in 7th European Conf. on Ant. and Pro. (EuCAP), pp. 220-223, 2013.

[13] M. Tajin, M. Ahmed and, P. K. Saha, "Performance Anal- ysis of an Ultra -Wideband Antenna for Wireless Capsule Endoscopy", in Proc. Int. Conf. Medical Engineering Health Informatics and Technology (MediTec), pp. 1-4, 2016.

[14] S. Mishra, R. Gupta and J. Mukherjee, "Parallel Metal Plated Tuning Fork Shape Omnidirectional Monopole Antenna for UWB applications," Micro. and Opt.Tech. Letters, vol. 53, no. 3, pp. 601-604, 2011.

[15] T. Neebha, M. Nesasudha, and D. Janapala, "A stable miniaturized AMC loaded flexible monopole an- tenna for ingestible applications," Computers in Biology and Medicine, Elsevier, pp.103578. Dec. 2019.

\section{Authors' Profiles}

P. More, A. Patil, G. Patil, and K. Thakur are Undergraduate students of A. C. Patil College of Engineering, Kharghar, Navi-Mumbai, affiliated to University of Mumbai, India.

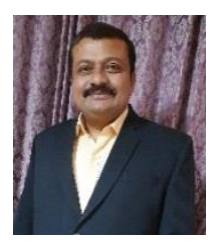

Dipak S. Marathe has submitted his Ph. D Thesis to University of Mumbai, and received the M. Tech. in Electronics from VJTI, Mumbai. He is currently Associate Professor in Electronics and Telecommunication Department at A. C. Patil College of Engineering, Navi-Mumbai, Maharashtra, India. His research interests include Analog and Digital CMOS VLSI Design, and Wireless Communication. 
How to cite this paper: P. More, A. Patil, G. Patil, K. Thakur, D. Marathe, " UWB Circular Fan-Shaped Monopole Patch Antenna", International Journal of Wireless and Microwave Technologies(IJWMT), Vol.11, No.2, pp. 32-38, 2021.DOI: 10.5815/ijwmt.2021.02.04 